Utah State University

DigitalCommons@USU

Marketing and Strategy Faculty Publications

Marketing and Strategy

$2-1-2020$

\title{
Filling the Organ Donor Pool by Giving Priority
}

Matthew D. Meng

Utah State University, matthew.meng@usu.edu

Roberta N. Clarke

Boston University

Follow this and additional works at: https://digitalcommons.usu.edu/marketing_facpub

Part of the Marketing Commons

\section{Recommended Citation}

Matthew D. Meng, Roberta N. Clarke; Filling the Organ Donor Pool by Giving Priority. J Health Polit Policy Law 1 February 2020; 45 (1): 49-71. doi: https://doi.org/10.1215/03616878-7893567

This Article is brought to you for free and open access by the Marketing and Strategy at DigitalCommons@USU. It has been accepted for inclusion in Marketing and Strategy Faculty Publications by an authorized administrator of DigitalCommons@USU. For more information, please contact digitalcommons@usu.edu.

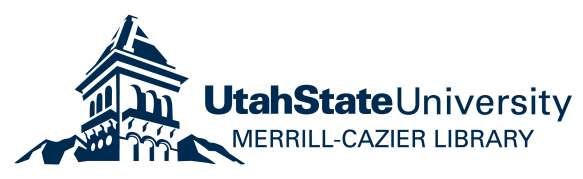




\title{
Filling the Organ Donor Pool by Giving Priority
}

\author{
Matthew D. Meng \\ Utah State University
}

Roberta N. Clarke

Boston University

\begin{abstract}
Context: Many of the alternatives for procuring donor organs are considered either ineffective, unethical, or illegal. One possibility that may not face such challenges is a priority system whereby individuals who register as an organ donor are given priority to receive an organ over those who have not registered. However, providing extrinsic rewards can sometimes paradoxically reduce the target behavior, especially for those who are more altruistically motivated.

Methods: Two behavioral experiments were employed and data were analyzed using regressions as well as examining open-ended responses.

Findings: The results suggest that giving priority to receive an organ to those who register to donate postmortem could increase overall registration rates. Further, the effect of providing priority appears to work by inducing anticipated regret, which can be used to overcome common obstacles to registration. Finally, it was found that a priority system is most effective in increasing donor rates for those individuals who are less altruistically motivated and does not reduce registration rates for those who are more altruistically motivated.

Conclusions: Given the unabated shortage of transplant organs, the finding that a priority system could increase the willingness to register as a donor without crowding out altruistically motivated individuals is highly encouraging.
\end{abstract}

Keywords organ donation, priority, anticipated regret, altruism, crowding out

Increasing the number of viable organs for transplantation is of the utmost importance. The United States leads the world in transplantations performed and has the fourth highest donor rate per capita (Lupkin 2013). However, over 114,000 people remain on the waiting list to receive an organ in order to survive, with an estimated 20 people dying each day for 
lack of an organ (HHS n.d.). Even with high awareness levels (98\% of US adults are aware of the need for organ donation), only $54 \%$ of US adults have registered to be organ donors postmortem (HHS n.d.). Thus, developing policies to increase organ donor registration is exceedingly important. Each donor can donate to save up to eight lives by bestowing multiple organs (AOPO n.d.; Johnson and Goldstein 2003; Kessler and Roth 2012; OPTN n.d.), meaning any increase in donors could have a substantial effect on increasing the availability of organs, even though only $2 \%$ of deaths are medically suitable for transplantation (CORE n.d.).

The United States currently utilizes an "opt-in" system for organ donation, whereby organs cannot be procured from a deceased donor without explicit consent from either the individuals before their deaths or from their families after death (Cameron et al. 2013) and with no direct or personal benefit to the deceased or their relatives. Individuals can opt into the donor pool when they obtain a driver's license or through an online organ registry. The Anatomical Gift Act of 2006 (ULC 2018) barred family members from overriding an individual's decision to donate. While it has been the law that an individual's consent to donate was legally binding, until the past few years, it was the practice of the Association of Organ Procurement Organizations to also gain the consent of the family members. However, this practice changed as online registration evolved, and now registered donations may take place even when the family objects (Glazier 2018).

To date, the primary approach to increasing the number of registered organ donors in the United States has been to appeal to altruism (Joralemon and Cox 2003), with many state registry campaigns based on the "Gift of Life" appeal and others encouraging individuals to "Become a hero for life" (Feeley 2007: 243). The altruistic approach relies on an individual's intrinsic motivation to contribute to society through registration. Although there were a record number of organs transplanted in the United States in 2017 and the list of those waiting for an organ has minimally declined since 2015, the number of people remaining on the waiting list was greater than three times the number of transplants performed (OPTN n.d.). So while 2017 was a record year for transplants $(35,000$ people received organs), more than 50,000 people were added to the waitlist (Alcorn 2018). The growth in transplanted organs is due in part to the usage of organs that would previously have been discarded (Glicksman 2018) as well as a dramatic increase in drug overdose deaths (Torjesan 2018). Thus, as has been true for decades, with the demand for organs exceeding the supply, motivations to register as an organ donor beyond the altruism approach are needed. 
As an alternative, the current research examines the effectiveness of a donation system that provides an extrinsic motive (i.e., external to the individual) to become an organ donor. Specifically, a priority system (also known as a mutual insurance pool; Schwindt and Vining 1998) gives those who register to donate postmortem a higher place on the list to receive an organ (compared to those who have not registered), should they need one. Similar systems have been implemented in countries outside the United States with some success. For example, in 2010 Israel implemented a law to give priority points to those who had signed up to become an organ donor postmortem. Under this system, individuals are able to gain differing degrees of priority either through consenting to donate their own organs after death, making a nondirected live donation, or being a first-degree relative of someone who registered as an organ donor, even if they are not registered themselves (Cronin 2014). If they were to need an organ transplant, they would receive priority over an otherwise equally matched individual who was not registered. In the first year of the program, deceased organ donation rates increased $46 \%$ from 7.8 to 11.4 donors per million and the number of registered donors increased from 10\% to almost 14\% (Lavee et al. 2013). However, the differences between countries in terms of the base percent of registered donors (54\% in the United States vs. $10 \%$ in Israel) as well as culture differences limit the applicability of these findings to the United States without further research.

Most of the studies examining the viability of introducing a similar priority system in the United States have elicited attitudes toward such systems using survey research or qualitative methods. For example, Spital (2005) surveyed American adults and found 53\% were in favor of a priority system, and Jasper et al. (1999) found that 54\% of existing American adult nondonors would choose to donate under a priority system. Although there is initial support for the introduction of a priority system, the general consensus appears to be that more research is required before implementing similar systems in countries such as the United States.

One notable example of research utilizing an experimental methodology to examine organ donor behavior (as opposed to relying on self-reported attitudes) is that by Kessler and Roth (2012). Using a decision-game paradigm, the authors tested the potential impact of a priority registration system in the United States. They found that giving allocation priority for those on a waiting list could have a positive impact on registration. However, in their experimental game, no explicit mention of organs was made. Instead, participants were given the opportunity to pay money to receive 
"units" that could enhance their chances of staying "alive" in the game. That is, the realities of organ donation, with preexisting beliefs and associated emotions were absent, meaning it cannot be certain a priority system will be well received in the United States based on these results alone. Further, there has yet to be an investigation into why a priority system works at encouraging individuals to register as an organ donor. Specifically, a priority system may elicit anticipated regret. Individuals may be motivated to avoid a situation where they are in need of an organ but potentially unable to receive one due to failure to have registered as a donor, placing them too far below others who have registered as donors.

Regret, and more specifically anticipated regret, is a strong predictor of behavior (Brewer, DeFrank, and Gilkey 2016). It has been shown to influence a number of health-related behaviors such as contraception use (Richard, Vries, and Pliget 1998) and giving blood (Godin et al. 2005). Anticipated regret has also been shown to be a potential tool to overcome common barriers to organ donor registration (O'Carroll et al. 2011). Rather than deleting the who section, can you put back in the sentence "In the current context, making salient the potential need for an organ could create anticipated regret in some individuals, resulting in a decision to register in order to increase one's chances of receiving an organ. Although the effectiveness of a priority system (Kessler and Roth 2012) and anticipated regret (O'Carroll et al. 2011) have been tested separately in relation to organ donor registration, no study has explored whether anticipatory regret could play a role in encouraging individuals to register under a priority system. O'Carroll et al. (2011) found that manipulating anticipated regret by explicitly asking participants if they would feel regret if they did not register significantly increased reported organ donor registrations. This finding showed the powerful influence of anticipated regret can have on intentions and behavior related to registering as an organ donor. However, in a large-scale field study, the opposite effect was found: that an anticipated regret intervention decreased registration rates, presumably because the questionnaire primed negative perceptions of organ donations (O'Carroll et al. 2016). Thus, a more implicit method of priming anticipated regret, such as through providing priority, may be more effective. On the downside, the introduction of an extrinsic reward - that is, receiving priority - for registering as an organ donor could backfire by decreasing the likelihood of certain individuals registering for altruistic reasons.

Intrinsic motivation arises from the value an individual gains personally and privately, such as pure altruism toward increasing others' well-being (Ariely, Bracha, and Meier 2009). Those motivated by altruistic reasons 
tend to donate to feel good about themselves and their actions (Dawson 1988), through their empathy toward someone in need (Batson and Coke 1981) and desire to help (Supphellen and Nelson 2001). Psychological benefits stem from intangible intrinsic benefits that an individual personally receives, or costs they have personally avoided, by helping others (Bekkers and Wiepking 2011). By giving, donors can experience affirmative psychological consequences in the form of a warm glow (Andreoni, 1990) or empathic joy (Batson and Shaw 1991).

However, Mellström and Johannesson (2008) found that changing the process for recruiting blood donors from a social approach (e.g., helping others) to an economic approach (e.g., receive payment) decreased the supply of donors by almost half. When extrinsic rewards and incentives to donate are offered, the question of whether someone is acting prosocially to do good becomes harder to answer (Ariely, Bracha, and Meier 2009), and extrinsic rewards may tarnish the reputational reward of acting prosocially (Bénabou and Tirole 2006), paradoxically resulting in a decrease in the target behavior. That is, with the inclusion of an extrinsic reward or payment, the positive signal to others that one is altruistic is diminished, with others potentially considering that individual to be greedy or selfish (Ariely, Bracha, and Meier 2009). Therefore, could providing priority (i.e., an extrinsic benefit) have a negative impact on registration rates for altruistically motivated individuals, resulting in a "crowding out" (Frey and Oberholzer-Gee 1997) of these potential donors?

The purpose of this research is to (a) examine whether the increase in intentions to donate organs using a priority system is still present when using a more realistic analog for the actual process of registering as an organ donor in the United States, (b) understand why individuals who have not registered as organ donors are more likely to register under a priority system, and (c) test whether providing an extrinsic benefit negatively affects the registration likelihood for those who are motivated to donate for primarily altruistic reasons. We report the results of two experiments that examine these issues. Our results hold implications for the design and introduction of a priority system for organ donation in the United States.

\section{Study 1}

The purpose of Study 1 is to provide an initial test of the effectiveness of providing priority for receiving an organ on the likelihood to register as a donor. In addition, we explore motivations for decisions to donate. 


\section{Method}

Two hundred and one participants from across the United States $\left(M_{\text {Age }}=\right.$ $36.62, S D=11.83 ; 53 \%$ female) who were not registered as organ donors were recruited online through Amazon's Mechanical Turk (MTurk) and were paid a nominal fee for participating. Data collection was not terminated until the desired sample size was met. Recruiting through MTurk allowed us to organically recruit a diverse set of people that have been shown to correspond with national probability samples (Coppock 2018). The advertisement posted to MTurk explicitly asked for participants not currently registered as an organ donor. As an extra screening procedure, the survey began with the question "To the best of your knowledge, are you currently registered to be an organ donor (that is, to have your organs donated should you die)?" (Yes, No, Not Sure). Those who did not answer "No" were told they did not qualify for the study and were unable to proceed through the survey. This initial question should not have appeared out of place given the survey was openly about organ donation opinions of existing nondonors. Though participants self-reported their own registration status, and proportions were in line with the national average, we cannot verify if all responses were accurate.

Two written responses were found to be identical indicating the presence of a repeat participant, so these two responses were removed from the data set. The analyses were performed using the remaining 199 data points.

After agreeing to participate in the study and passing through the aforementioned screening question, participants were asked to "Imagine you are renewing your license today. If you were faced with the following prompt during this process regarding becoming an organ donor, what would your response be?" All participants were told to "Select the choice that reflects your wishes," but those randomly assigned to the Priority condition were also told that "registering as an organ donor will get you placed higher on the list to receive an organ should you need one." (They were debriefed at the end of the experiment that this was not true). Those in the Control condition were not given any extra information. Next, all participants indicated whether they would be willing to join the donor registry ("Yes, I want to join the Donor Registry" vs. "No, I do not want to join the Donor Registry"), which was used as the dependent variable. On the subsequent page of the survey, all participants were then asked to write a minimum of 250 characters explaining what motivated them to indicate they would or would not register as an organ donor. These open-ended responses were used to qualitatively explore the motivations behind why individuals act in this situation and why introducing a priority system might entice 
individuals to register as a donor. The survey concluded with participants answering demographic-related questions (e.g., age, gender; see appendix for results). If the repeat participants' responses were included, the results remained unchanged.

\section{Results and Discussion}

Effect of Priority. A logistic regression was used to examine whether registration likelihood varied across conditions. Specifically, we expected higher registration likelihood when participants were told that they would receive priority for registering. The prompt variable (coded: Control $=0$, Priority $=1$ ) was included as the independent variable and the registration choice (coded: Did not register $=0$, Registered $=1$ ) was included as the dependent variable. As expected, participants in the Priority condition were significantly more likely to register as an organ donor $(55 \%)$ compared to those in the Control condition $\left(39 \%, \beta=.64, \mathrm{SE}=.28, \chi^{2}=4.82\right.$, $p<.05)$.

Open-Ended Responses. Examining the open-ended responses revealed qualitative insights as to why the priority system works. All open-ended responses were read and coded by two independent coders who were aware of the hypothesis and conditions. In situations where multiple reasons were provided by a participant, the coders made judgements as to which was the "primary" reason. Any discrepancies in coding (87\% agreement) were discussed and agreed on. Table 1 and table 2 show the frequencies of each primary reason provided. Descriptions of each category are included in table 3.

From Table 1 it can be seen that Discomfort, Incentive-Driven Mistrust, and a Lack of Knowledge are the three most cited reasons for choosing not to register as an organ donor, accounting for $28.3 \%, 20.0 \%$, and $11.7 \%$ of respondents respectively. The other reasons (i.e., Religion/Spirituality, Competence-Driven Mistrust, Perceived Ineligibility, No Directed Donation, Effort, and Not Sure/No Reason) all accounted for less than 10\% each. However, for those offered priority, the proportion of respondents providing Discomfort, Lack of Knowledge, Religion/Spirituality, No Directed Donation, and Effort as reasons for not registering was lower, with Discomfort experiencing the greatest proportional decrease. Conversely, the proportion of respondents providing Incentive-Driven Mistrust, CompetenceDriven Mistrust, Perceived Ineligibility, Not Sure/No Reason, and Unfair as reasons for not registering increased. For those in table 1, there was a marginally significant association between priority system and the reasons provided for not registering as an organ donor $\left(\chi^{2}=16.22, p<.10\right)$, 
Table 1 Frequencies of Reasons for Indicating "No" to Registering as an Organ Donor in Study 1

\begin{tabular}{lrrrrr}
\hline & \multicolumn{2}{c}{ Control } & & \multicolumn{2}{c}{ Priority } \\
\cline { 2 - 3 } \cline { 5 - 6 } Reason & $\mathrm{n}$ & $\%$ & & $\mathrm{n}$ & $\%$ \\
\hline Discomfort & 17 & 28.3 & & 17.8 \\
Incentive-driven mistrust & 12 & 20.0 & & 10 & 22.2 \\
Lack of knowledge & 7 & 11.7 & & 4.4 \\
Religion/spirituality & 4 & 6.7 & & 1 & 2.2 \\
Competence-driven mistrust & 3 & 5.0 & & 3 & 6.7 \\
Perceived ineligibility & 2 & 3.3 & & 7 & 17.8 \\
No directed donation effort & 2 & 3.3 & & 0 & 0.0 \\
Not sure/no reason & 2 & 3.3 & & 3 & 6.7 \\
Unfair & 0 & 0.0 & & 3 & 6.7 \\
\hline
\end{tabular}

Table 2 Frequencies of Reasons for Indicating "Yes" to Registering as an Organ Donor in Study 1

\begin{tabular}{lrrrrr} 
& \multicolumn{2}{c}{ Control } & & \multicolumn{2}{c}{ Priority } \\
\cline { 2 - 3 } \cline { 5 - 6 } Reason & $\mathrm{n}$ & $\%$ & & $\mathrm{n}$ & $\%$ \\
\hline Altruism & 34 & 87.2 & & 21 & 38.2 \\
Fairness/reciprocity & 3 & 7.7 & & 0 & 0.0 \\
Not sure/no reason & 2 & 5.1 & & 1 & 1.8 \\
Benefits of priority & 0 & 0.0 & & 32 & 58.2 \\
Personal experience & 0 & 0.0 & & 1 & 1.8 \\
\hline
\end{tabular}

providing evidence that the relative weight of certain reasons was different for those offered priority. Much of this result can assumedly be driven by Discomfort, as it experienced the greatest difference in proportion of respondents providing it as the primary reason for not registering.

From table 2, it can be seen that Altruism was stated by most of the respondents $(87.2 \%)$ as the reason for choosing to register as an organ donor, with Fairness/Reciprocity and Not Sure/No Reason accounting for the remaining $12.8 \%$. For those offered priority, the proportion of respondents providing Altruism, Fairness/Reciprocity, and Not Sure/No Reason as reasons for registering was lower than those in the control condition. Notably, those indicating Benefits of Priority as the primary reason account for the majority of respondents under the priority system (58.2\%). Personal Experience also experienced an increase, although this was only a single respondent. For those in table 2, there was a significant association between 
Table 3 Category Definitions and Examples of Reasons to Register or Not Register in Study 1

\begin{tabular}{|c|c|}
\hline Reason Categories & Reason Examples \\
\hline Altruism & The right/moral thing to do. \\
\hline Benefit of priority & $\begin{array}{l}\text { Would have a greater chance at receiving an organ } \\
\text { should they need one. }\end{array}$ \\
\hline Body kept intact & $\begin{array}{l}\text { Fear of mutilation. } \\
\text { Funeral appearance considerations. } \\
\text { Need organs in the afterlife. }\end{array}$ \\
\hline $\begin{array}{l}\text { Competence based } \\
\text { mistrust }\end{array}$ & $\begin{array}{l}\text { Physicians may incorrectly pronounce patients } \\
\text { brain-dead. } \\
\text { May be conscious and aware during organ removal } \\
\text { process. }\end{array}$ \\
\hline Discomfort & $\begin{array}{l}\text { Do not like to think about death. } \\
\text { Do not like to think about having their organs } \\
\text { removed and placed in someone else. } \\
\text { The process is unnatural. }\end{array}$ \\
\hline Effort & $\begin{array}{l}\text { Do not have the motivation to go through the } \\
\text { process of registering. }\end{array}$ \\
\hline Fairness/reciprocity & $\begin{array}{l}\text { Believe that if they want to receive an organ then } \\
\text { they should be willing to donate an organ. }\end{array}$ \\
\hline Incentive-based mistrust & $\begin{array}{l}\text { That physicians may not try as hard to save their } \\
\text { life if they are registered as a donor. } \\
\text { Hospitals are incentivized to let you die. }\end{array}$ \\
\hline Lack of knowledge & $\begin{array}{l}\text { Need to know more about the process of organ } \\
\text { donation before making a decision. } \\
\text { Need to talk to family more before making a } \\
\text { decision. }\end{array}$ \\
\hline No direct donation & $\begin{array}{l}\text { Cannot stipulate that their organs go to family } \\
\text { or friends. } \\
\text { Cannot stipulate that their organs will not go to } \\
\text { someone "undeserving." }\end{array}$ \\
\hline No reason/not sure & No reason specifically provided. \\
\hline Perceived ineligibility & $\begin{array}{l}\text { Believe that they are too unhealthy or too old to } \\
\text { register as a donor. }\end{array}$ \\
\hline Personal experience & $\begin{array}{l}\text { Someone close to them needed an organ, which } \\
\text { was used as motivation to register. }\end{array}$ \\
\hline Religion/spirituality & Religion precludes them from donating. \\
\hline Unfair & $\begin{array}{l}\text { The priority system is unfair so they opt to not } \\
\text { register as a donor. }\end{array}$ \\
\hline
\end{tabular}


priority system and the reasons provided for registering as an organ donor $\left(\chi^{2}=37.78, p<.001\right)$. This provides evidence that the proportion of certain reasons provided for registering or not registering as a donor was significantly different when priority was offered, driven largely by the increase in participants citing the benefits of the priority system as the primary reason for registering as an organ donor.

Given that the Discomfort reason experienced the greatest decline in proportional frequency of use, this suggests that individuals who feel uncomfortable (i.e., the "Discomfort" category) when considering being an organ donor may be the most influenced by the introduction of the priority system. Examining participants' (i.e., those who indicated "Yes") openended responses uncovered support for this conclusion. As an example, one participant wrote: "My initial reaction was a bit of wariness, since while I intellectually get that giving an organ is a good and helpful thing, there is something my mind finds off about the idea of someone else having my organs after I'm dead. ... But then I imagined myself in the situation where *I* needed an organ, and how much I would regret not being on the list then. That potential benefit was enough to push me past my hesitation and squeamishness."

Intuitively, this makes sense. Those who indicated, for example, that they would like to learn more or that they do not trust the medical profession are less likely to be influenced by the priority prompt. However, those who realize that organ donation is a noble gesture but feel discomfort when considering the reality of donating an organ are likely to overcome this discomfort and register.

The results of tables 1 and 2 also suggest that anticipated regret may play an important role in deciding whether to register as an organ donor under a priority system. To qualitatively examine this finding, we reviewed the open-ended responses of those who chose to become an organ donor under the priority system. In these responses there are several instances of individuals discussing their anticipated regret. For example, responses such as "I think that if I was in a really bad need for an organ and I was on the list to receive an organ I would really want to make sure that I had the best possible chance of getting a new organ" and "I would like to be able to live if I were to ever get into a really bad accident, and if that's all I have to do, well then that's what I would do" suggest that participants realized that if they don't register and they become in need of an organ, they may not receive one under a priority system. Other participants talked about wanting to ensure they would remain alive for their children, or that "Lists for organs can be long and sometimes people die before receiving what they need. I would definitely be influenced by an indication that the wait times 
could be reduced for those just as willing to give as receive" and "When you put your life into the equation and get a personal benefit, i.e., possibly living vs. dying, that carries a powerful motivation."

Beyond the motivating aspects of the priority system, there were contrasting insights gleaned from the open-ended responses as well. Specifically, some individuals indicated they would not register under a priority system because it was considered unfair. That is, even though they saw the altruistic benefits of being a donor, they felt that being given priority over someone else was prejudicial, so they opted not to register. This reveals the potential of crowding out altruistically motivated individuals after the introduction of a priority system. This issue is further addressed in study 2 .

Overall, this initial study supports previous research that suggests a priority system may entice individuals to register as organ donors (e.g., Kessler and Roth 2012) and that, for many, there are several different obstacles to registering (e.g., Burkell, Chandler, and Shemie 2013). Interestingly, it appears that a priority system may be able to overcome some of these obstacles by providing a personal incentive. However, providing extrinsic rewards can potentially backfire by discouraging more altruistically motivated individuals from acting (Frey and Oberholzer-Gee 1997).

\section{Study 2}

The aim of study 2 is to extend the findings from study 1 in two ways. First, a more realistic paradigm is used, and second, whether those who are more altruistically motivated are "crowded out" by the inclusion of the extrinsic reward of priority is examined.

\section{Method}

Five hundred and six participants from all across the United States were recruited online through Amazon's Mechanical Turk and were paid a nominal fee for participating. Data collection was not terminated until the desired sample size was met. This sample included 211 participants who said they were not currently registered to be organ donors $\left(M_{\mathrm{Age}}=33.38\right.$, $S D=10.07 ; 42 \%$ female) and 276 participants who said they were currently registered $\left(M_{\text {Age }}=33.99, S D=9.54 ; 45 \%\right.$ female $)$. Nineteen participants who said they were not sure if they were registered or not were omitted from the analyses $\left(M_{\text {Age }}=33.52, S D=10.47 ; 53 \%\right.$ female $)$.

Participants were informed that they would be evaluating a section of a new Registry of Motor Vehicles (RMV) website, specifically the section of the website that will be used for the license renewal process. This cover 
story allowed us to elicit organ donation requests in a more naturalistic context without revealing the true motivations of the research.

First, participants were shown a mock-up of the RMV homepage and asked questions consistent with the cover story (e.g., How simple is the homepage?). Second, participants were shown the introductory screen to the driver's license renewal page and also asked similar questions consistent with the cover story. Third, participants began the process of renewing their license where they were given descriptions of the different types of licenses, and were instructed to click on the type of license they wanted to renew. Then participants were randomly assigned to see one of two different organ donation pages under the guise of being "Step 2" in the license renewal process. Those randomly assigned to the Control condition were asked to "Select the option that reflects your wishes" ("Yes, I want to join the Donor Registry" vs. "No, I do not want to join the Donor Registry"). The wording used in this study is similar to that used by many state registries. Those randomly assigned to the Priority condition were told "People who sign up to be an organ donor are placed higher on the list to receive an organ, should they need one" and then were provided with similar options as in the Control condition ("Yes, I want to join the Donor Registry and be given priority to receive an organ should I need one" vs. "No, I do not want to join the Donor Registry"). The dependent variable was whether the participant indicated they would register or not register. Although most donor registries do require people to make a choice, participants in both conditions were informed they were able to opt out of the decision simply by not selecting a response.

All participants then completed questions consistent with the cover story by rating the new website and providing feedback. Finally, participants answered demographic questions (e.g., gender, age; see appendix for results), whether they were in reality registered as an organ donor (Yes, No, Not Sure), and the 20-item altruism scale (Rushton et al. 1981), which was used to examine the presence of any crowding-out (Frey and OberholzerGee 1997). The altruism scale was asked last (i.e., after all of the non-organdonation-related demographic questions) to allow the greatest separation from the main survey. However, we cannot say with absolute certainty that the manipulation, registration questions, or decisions to register did not influence subsequent self-reported altruism.

\section{Results and Discussion}

To examine whether the effect of the priority prompt differed depending on an individuals' altruism level, we ran a binary logistic regression that 


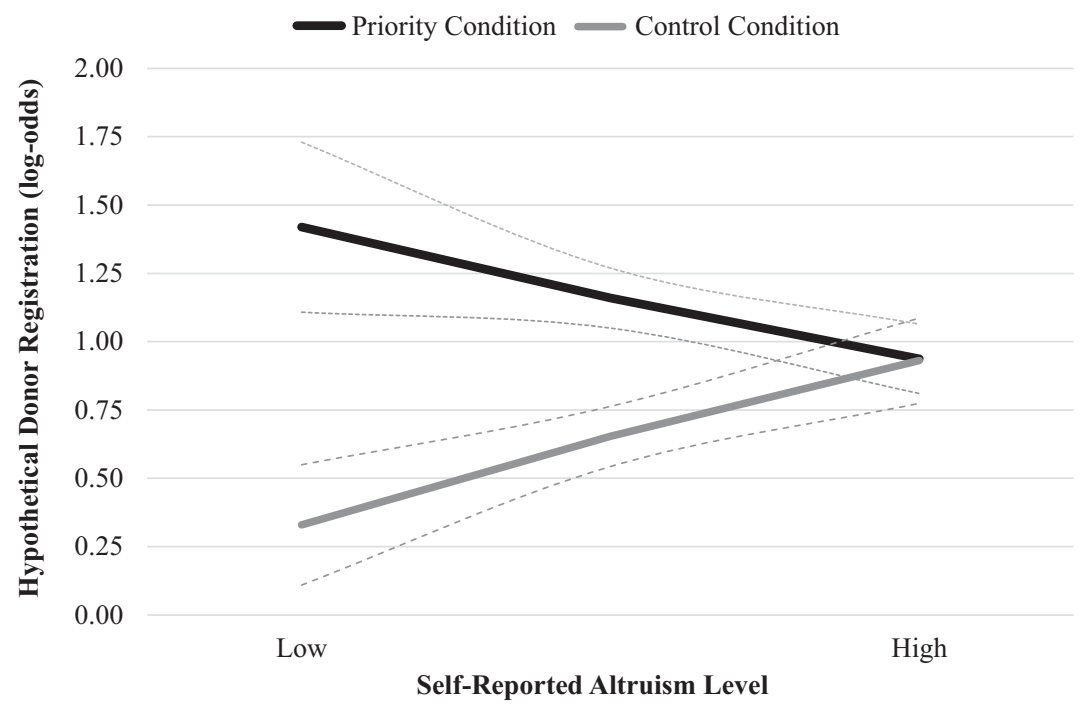

Figure 1 Interaction between presence/absence of priority and altruism on hypothetically registering as an organ donor for all participants.

included the prompt condition (coded: Control $=0$, Priority $=1$ ) and meancentered altruism $(\alpha=.93, M=2.81, S D=.71)$ as the independent variables, their respective interaction term, current donor status (coded: Non-Registered Donor $=-1$, Registered Donor $=1$ ) as a covariate, and participants' choice (coded: Did Not Register $=0$, Registered $=1$ ) as the dependent variable. The results revealed a significant effect of the priority prompt condition, whether the participant was previously registered as a prospective donor, and the interaction between the prompt and altruism. The main effect of altruism was not significant.

Thus, the effect of the priority system in encouraging registration relative to the current system is greater at lower levels of altruism, but not at higher levels (figure 1). In addition, no drop-off in registration likelihood is observed for those who scored high in altruism (i.e., no "crowding out" is found; table 5).

Because nondonors are the primary target for policy changes intended to increase donor registration rates, the same analysis was performed for the current nondonors only. The results revealed a significant effect of prompt condition and the interaction between the prompt and altruism. The main effect of altruism was not significant (table 4 ). That is, the priority prompt 
Table 4 Results from Study 2 on the Interaction of Registration Status, Altruism, and Prompt Conditions

\begin{tabular}{lrrc}
\hline & $\beta$ & $S E$ & Wald $\chi^{2}$ \\
\hline All participants: & & & \\
$\quad$ Prompt condition & 2.88 & 1.16 & $6.14^{*}$ \\
Altruism & .46 & .30 & 2.43 \\
Prompt and altruism & -.83 & .40 & $4.29^{*}$ \\
$\quad$ Registration status & 2.04 & .16 & $173.65^{*}$ \\
Nonregistered donors: & & & \\
$\quad$ Prompt condition & 3.94 & 1.41 & $7.82^{*}$ \\
Altruism & .42 & .37 & 1.29 \\
$\quad$ Prompt and altruism & -1.18 & .50 & $5.60^{*}$ \\
Registered donors: & & & $.01^{*}$ \\
$\quad$ Prompt condition & -.22 & 2.09 & 1.22 \\
Altruism & .62 & .57 & $.03^{*}$ \\
Prompt and altruism & .14 & .77 & \\
\hline
\end{tabular}

Note: $* p<.05$

Table 5 Probabilities of Registering as an Organ Donor in Study 2

\begin{tabular}{llccc}
\hline & & -1 SD altruism & Mean altruism & +1 SD altruism \\
\hline Registered donors & Control & 89 & 92 & 94 \\
$\%$ & Priority & 91 & 94 & 96 \\
Nonregistered donors & Control & 2 & 8 & 18 \\
$\%$ & Priority & 37 & 24 & 17 \\
\hline
\end{tabular}

significantly increased donor registration likelihood among nondonors compared to a control condition for those with lower altruism scores.

Finally, the same analysis was run with only the existing donors $\left(M_{\text {Altruism }}=2.88, S D=.67\right)$. Not surprisingly all effects failed to reach significance (table 4), further suggesting that those who may be more altruistically motivated are not more likely to avoid registering as an organ donor in the presence of a priority system.

Overall, these findings suggest that the introduction of a priority system could have a positive impact on the likelihood of registering as an organ donor for less altruistically motivated individuals. Importantly, a priority system may not significantly lessen altruistically motivated individuals' intentions to register relative to the current system. This provides evidence that "crowding out" of those who are more altruistically motivated to donate their organs should not occur with the addition of an extrinsic reward. 


\section{General Discussion}

This research explored an alternative approach to increasing donor registration rates by giving priority in organ allocation to those who register to donate in the event of their death. The results of the two experiments suggest that a priority system for organ donation could contribute to a larger donor pool and that less altruistic people are more motivated by the priority prompt (relative to the current system). Importantly, the use of a priority prompt would not reduce donation rates for those people who scored high on altruism. In other words, the priority system primarily appeals to those less altruistically motivated to donate their organs without "crowding out" those who are more altruistically motivated.

Our findings are consistent with earlier work by Kessler and Roth (2012), extending their work in a more realistic choice context that explicitly discusses organ donation, and testing for the presence of a crowding out effect potentially due to tarnishing the previously altruism-signaling behavior (Bénabou and Tirole 2006). Suggesting additional elaboration is the decision to refer to self-reported altruism as a proxy for intrinsic motivation (to be an organ donor) in the absence of strong empirical backing. Further, our findings differ from those of Burkell, Chandler, and Shemie (2013) by revealing that existing nondonors are actually more likely to register as a donor under a priority system. Finally, through the open-ended responses of study 1 , we were able to understand the motivations behind those who previously had not registered as an organ donor but indicated they would register if given priority. It appears that many of these individuals are motivated by anticipated regret. That is, by making the need for organs salient, and the opportunity to increase the chance of receiving one, individuals realize they would regret not being able to receive an organ, resulting in an increase in donor registrations. These open-ended responses also gave us insight into many of the obstacles individuals report for not registering as an organ donor (e.g., discomfort). Although the conclusions we have drawn are based on our findings, there is still the possibility of a separate, third variable such as those noted in table 1 , driving both registration choice and self-perceptions of altruism. Future research can attempt to uncover other important variables that could influence the efficacy of the priority system.

The priority system examined in this article has notable advantages over other proposed approaches to increasing organ donor registrations. For example, there have been calls for monetary payment for organs, an act that was expressly forbidden by Congress in the National Organ Transplant Act 
in 1984. The international transplant community has continued to reject monetary incentives as a motivator for postmortem organ donation (Leider and Roth 2010) mostly due to ethical concerns (Rothman 2002), even though it would likely expand the donor pool (Rosen, Vining, and Weimer 2011). A slight adjustment to the process to allow the direction of payment to charity could circumvent these ethical issues (Mellström and Johannesson 2008), however, this approach would still rely on altruism. Another proposed approach to increasing donor rates is to change the default from the current opt-in mode to an opt-out mode, where consent to donate is presumed. This approach has been implemented in 16 largely European countries (e.g., Spain, Belgium, France; Zúñiga-Fajuri 2015) with substantially increased donation rates (Johnson and Goldstein 2003) and is currently gaining traction in Britain and other European countries. Glazier (2018) notes that US culture deeply values individual rights, a mindset reflected in its laws, such that a legal gift of an organ would have to be an active "affirmative, voluntary decision" versus a passive presumption of consent. This is reaffirmed by repeated attempts in the United States to introduce presumed consent laws; these efforts have fallen short in states including Connecticut, Delaware, Illinois, Massachusetts, New York, Texas, Vermont, and others. Further, roughly half of the US population would not support an opt-out policy (HHS 2013) as there is a concern that implementing this policy would result in a loss of autonomy (Zink, Zeehandelaar, and Wertlieb 2005). Thus, the currently used approach (i.e., opt-in) and suggested alternatives to increasing organ donor registration all have notable negatives: altruism would not require legislation, but does not increase supply expeditiously enough to keep up with demand; monetary payments are unacceptable from both a legal and an ethical perspective, and; presumed consent, while effective in some countries, faces hurdles in gaining acceptance within the United States.

Therefore, such a priority system could be implemented with at least limited change to the enabling federal statute of the National Organ Transplant Act of 1984 (NOTA) to establish priority for registered donors. To incorporate such a policy into regulations governing organ allocation requires that NOTA be modified to incorporate nonmedical criteria (priority due to organ donor registration) in addition to the current medical criteria in allocation priority. However, in practice, this is already done as related to age and geography, but to establish this as policy would likely require regulatory change and might politically require the cover of legislative change. 
Despite the considerable increase in registered donors and resulting donations in Israel (Goldfarb 2012), there have been substantial criticisms of the donor-priority system that have to be considered. In reality, Israel's law did not work as well as it was expected to due to clauses in the law now being evaluated for change. First, a clause stated that only one member of the family needed to register in order for the whole family to receive priority for an organ; in large families, for example, only one family member would need to register to provide preferential status for all others in the family. Those with many direct family members have a greater potential to find a donor match, resulting in less dependence on the public donor pool, but these individuals would receive priority due to another member's registration (Quigley, Wright, and Ravitsky 2012). Second, there was some initial concern about individuals receiving immediate priority for registering as a donor, resulting in individuals waiting until they needed an organ to register. However, Israel's system circumvents this issue by implementing a three-year waiting period (or only one year for those who signed up before December 31,2011) before an individual is added to the priority list (Kessler and Roth 2014; Quigley, Wright, and Ravitsky 2012). Although a similar approach would address this issue in the United States, it also creates a new issue: any priority listing policy would likely not include pediatric transplant candidates. Underage patients cannot register as organ donors and cannot be held to a three-year waiting period at young ages. In order to avoid constricting young candidates, priority points for those between 18 and 21 years of age would need to be prorated. For example, if someone is listed for transplant at age 20 and they registered at age 18 , they could be given full priority points despite not having been registered for three years. Finally, as allowed by the Israeli law, some Israeli families have refused to donate their deceased relative's organs, even if the relative had registered as a donor, resulting in a "free-rider" problem (i.e., registering in order to receive an organ if needed without any intention to donate at the time of death; Kerr and Bruun 1983). However, this issue would not occur in the United States as registering as a donor is viewed as legally binding, so the families would not be asked prior to the procurement of organs (Costa et al. 2009; Mesich-Brant and Grossback 2005). Therefore, if introduced in the United States, it is recommended that (1) priority be given just to the registrant and not all direct family members, and (2) a certain waiting period be enforced (e.g., three years) before an individual is added to the priority list, unless they are under 21 when certain concessions could be made, and the decision of an individual to donate his or her organs in the event of their death continues to be enforced, even in the presence of family opposition, to eliminate any free-riding. 
Although the current findings are promising, there are limitations to the priority system itself. First, those who vehemently oppose organ donation and therefore refuse to register as a donor could arguably be "penalized" by remaining at the bottom of a donor list. This concern is supported by some individuals' responses in study 1 who chose not to register even if given priority due to it being an unfair system. Second, one could argue that the priority system will work only as long as registration provides a clear benefit in terms of placement on a list for receiving an organ. In that respect, if a priority system is too effective in encouraging registration, the perceived benefit of registering may seem too small. That is, if everyone registers under a priority system, no one really has an advantage in terms of receiving an organ. Still, if everyone were to register, the increased registration would result in there being many more organs available for transplant, thereby serving everyone's interests. Regardless of these potential issues, it appears the priority system has the ability to increase the donor pool, which would save countless lives.

\section{Conclusion}

Organ donation is a complex and dynamic area of need. Given the immense benefits and certainty of saving lives realized through a larger donor pool, it is important to continually examine areas to increase organ donor registration rates. With the shortage of organs continuing to surpass 100,000 people annually while 20 people die each day for lack of an organ, and with other proposed means to increase organ donor registration not meeting the need, being unwanted by the public, or being illegal, the prospect of implementing a priority system for donor registration becomes more attractive. The current findings suggest that a priority system would have a considerable effect on motivating people who are more self-interested to become organ donors, with no negative effect on the likelihood to register for those more altruistically motivated.

Matthew D. Meng is assistant professor at the Huntsman School of Business at Utah State University. His research aim is to examine how to use psychological principles to implement applied solutions that benefit the individual, others around them, or society in general.

matthew.meng@usu.edu 
Roberta N. Clarke is associate professor emeritus in the Health Sector Management Program in Boston University's Questrom School of Business. She coauthored Marketing for Health Care Organizations with Philip Kotler and was the first person to receive the American Marketing Association's Award for Excellence in Healthcare Marketing. She has focused her research on a broad range of health care marketing issues and is currently serving as an expert witness for the US Department of Justice on concerns related to pharmaceutical marketing.

\section{References}

Alcorn, Ted. 2018. "Thousands of Organs Are Lost before They Can Be Donated. Here's How to Save Them." Vox, March 25. www.vox.com/science-and-health /2018/4/23/17267884/organ-donation-transplant-liver-kidney.

ANES (American National Election Studies). n.d. "Liberal-Conservative SelfIdentification 1972-2016." ANES Guide to Public Opinion and Electoral Behavior. electionstudies.org/resources/anes-guide/top-tables/?id=29 (accessed August 20, 2019).

Andreoni, James. 1990. "Impure Altruism and Donations to Public Goods: A Theory of Warm-Glow Giving.” Economic Journal 100, no. 401: 464-77.

Ariely, Dan, Anat Bracha, and Stephan Meier. 2009. "Doing Good or Doing Well? Image Motivation and Monetary Incentives in Behaving Prosocially." American Economic Review 99, no. 1: 544-55.

AOPO (Association of Organ Procurement Organizations). n.d. "Organ Procurement and Transplantation Network (OPTN) Data." Data on Donation and Transplantation. www.aopo.org/related-links-data-on-donation-and-transplantation/ (accessed August 20, 2019).

Batson, C. Daniel, and Jay S. Coke. 1981. "Empathy: A Source Altruistic Motivations for Helping." In Altruism and Helping Behavior: Social, Personality, and Developmental Perspectives, edited by J. Philippe Rushton and Richard M. Sorrentino, 167-87. Hillsdale, NJ: Eribaum.

Batson, C. Daniel, and Laura L. Shaw. 1991. "Evidence for Altruism: Toward a Pluralism of Prosocial Motives." Psychological Inquiry 2, no. 2: 107-22.

Bekkers, René, and Pamala Wiepking. 2011. "A Literature Review of Empirical Studies of Philanthropy: Eight Mechanisms that Drive Charitable Giving." Nonprofit and Voluntary Sector Quarterly 40, no. 5: 924-73.

Bénabou, Roland, and Jean Tirole. 2006. "Incentives and Prosocial Behavior." American Economic Review 96, no. 5: 1652-78.

Brewer, Noel T., Jessica T. DeFrank, and Melissa B. Gilkey. 2016. "Anticipated Regret and Health Behavior: A Meta-Analysis.” Health Psychology 35, no. 11: 1264-75.

Burkell, Jacquelyn A., Jennifer A. Chandler, and Sam D. Shemie. 2013. "Attitudes toward Reciprocity Systems for Organ Donation and Allocation for Transplantation." Journal of Health Politics, Policy and Law 38, no. 5: 957-86. 
Cameron, Andrew M., Allan B. Massie, Charles E. Alexander, B. Stewart, Robert A. Montgomery, N. R. Benavides, G. D. Fleming, and Dorry L. Segev. 2013."Social Media and Organ Donor Registration: The Facebook Effect." American Journal of Transplantation 13, no. 8: 2069-65.

CORE (Center for Organ Recovery and Transplantation). n.d. "Donation Process." www .core.org/understanding-donation/donation-process/ (accessed August 20, 2019).

Coppock, Alexander. 2018. "Generalizing from Survey Experiments Conducted on Mechanical Turk: A Replication Approach.” Political Science Research and Methods 7, no. 3: 613-28. doi.org/10.1017/psrm.2018.10.

Costa, Alessandro N. et al. 2009. "A Colloquium on the Congress 'A Gift for Life': Considerations on Organ Donation.” Transplantation 88, no. S7: S108-158.

Cronin, Antonia. 2014. "Points Mean Prizes: Priority Points, Preferential Status, and Directed Organ Donation in Israel." Israel Journal of Health Policy Research 3, no. 1: 8 .

Dawson, Scott. 1988. "Four Motivations for Charitable Giving: Implications for Marketing Strategy to Attract Monetary Donations for Medical Research.” Journal of Health Care Marketing 8, no. 2: 31-37.

Feeley, Thomas H. 2007. "College Students' Knowledge, Attitudes, and Behaviors Regarding Organ Donation: An Integrated Review of the Literature." Journal of Applied Social Psychology 37, no. 2: 243-71.

Frey, Bruno S., and Felix Oberholzer-Gee. 1997. "The Cost Price of Incentives: An Empirical Analysis of Motivated Crowding-Out.” American Economic 87, no. 4: 746-55.

Glazier, Alexandra K. 2018. "Organ Donation and the Principles of Gift Law." Clinical Journal of American Society of Nephrology 13, no. 8: 1283-84.

Glicksman, Eve. 2018. "New Life for Less-Than-Perfect Organs." Association of American Medical Colleges, AAMC News, May 29. news.aamc.org/research /article/new-life-less-perfect-organs/.

Godin, Gaston, Paul D. Sheeran, Mark Conner, Marc Germain, Danielle Blondeau, Camille Gagné, Danie Beaulieu, and Herminé Naccache. 2005. "Factors Explaining the Intention to Give Blood among the General Population." Vox Sanguinis 89, no. 3 : $140-49$.

Goldfarb, David A. 2012. "Re: A New Law for Allocation of Donor Organs in Israel." Journal of Urology 188, no. 4: 1297.

HHS (US Department of Health and Human Services). 2013. 2012 National Survey of Organ Donation Attitudes and Behaviors. September. www.organdonor.gov/sites /default/files/about-dot/files/nationalsurveyorgandonation.pdf.

HHS (US Department of Health and Human Services). n.d. Organ Donation Statistics. www.organdonor.gov/statistics-stories/statistics.html\#registration (accessed August 20, 2019).

Jasper, John D., C. A. E. Nickerson, John C. Hershey, and David A. Asch. 1999. "The Public's Attitudes toward Incentives for Organ Donation." Transplantation Proceedings 31, no. 5: 2181-84.

Johnson, Eric, and Daniel Goldstein. 2003. "Do Defaults Save Lives?” Science 302, no. 5649: 1338-39. 
Joralemon, Donald, and Phil Cox. 2003. "Body Values: The Case against Compensating for Transplant Organs." Hastings Center Report 33, no. 1: 27-33.

Kerr, Norbert L., and Steven E. Bruun. 1983. "Dispensability of Member Effort and Group Motivation Losses: Free-Rider Effects.” Journal of Personality and Social Psychology 44, no. 1: 78-94.

Kessler, Judd B., and Alvin E. Roth. 2012. "Organ Allocation Policy and the Decision to Donate.” American Economic Review 102, no. 5: 2018-47.

Kessler, Judd B., and Alvin E. Roth. 2014. "Loopholes Undermine Donation: An Experiment Motivated by an Organ Donation Priority Loophole in Israel." Journal of Public Economics 114, June: 19-28.

Lavee, Jacob, Tamar Ashkenazi, Avi Stoler, Jonathan Cohen, and Rafael Beyar. 2013. "Preliminary Marked Increase in the National Organ Donation Rate in Israel Following Implementation of a New Organ Transplantation Law." American Journal of Transplantation 13, no. 3: 780-85.

Leider, Stephen, and Alvin E. Roth. 2010. "Kidneys for Sale: Who Disapproves, and Why?" American Journal of Transplantation 10, no. 5: 1221-27.

Lupkin, Sydney. 2013. "Organ Donation Rates: How the US Stacks Up.” ABC News, June 18. abcnews.go.com/Health/organ-donation-rates-us-stacks/story?id=1943 7070\#1.

Mellström, Carl, and Magnus Johannesson. 2008. "Crowding Out in Blood Donation: Was Titmuss Right?” Journal of the European Economic Association 6, no. 4: 845-63.

Mesich-Brant, Jennifer L., and Lawrence J. Grossback. 2005. "Assisting Altruism: Evaluating Legally Binding Consent in Organ Donation Policy.” Journal of Health Politics, Policy and Law 30, no. 4: 687-717.

O'Carroll, Ronan E., Jennifer Dryden, Tiffany Hamilton-Barclay, and Eamonn Ferguson. 2011. "Anticipated Regret and Organ Donor Registration: A Pilot Study." Health Psychology 30, no. 5: 661-64.

O'Carroll, Ronan E., Lee Shepherd, Peter C. Hayes, and Eamonn Ferguson. 2016. "Anticipated Regret and Organ Donor Registration: A Randomized Controlled Trial." Health Psychology 35, no. 11: 1169-77.

OPTN (Organ Procurement and Transplantation Network). n.d. Board Actions. optn .transplant.hrsa.gov/search-results?q=board\%20actions (accessed September 19, 2019).

Quigley, Mauireann, Linda Wright, and Vardit Ravitsky. 2012. "Organ Donation and Priority Points in Israel: An Ethical Analysis.” Transplantation 93, no. 10: 970-73.

Richard, René, Nanne K. Vries, and Joop Pligt. 1998. "Anticipated Regret and Precautionary Sexual Behavior." Journal of Applied Social Psychology 28, no. 15: 1411-28.

Rosen, Lara, Aidan R. Vining, and David L. Weimer. 2011. "Addressing the Shortage of Kidneys for Transplantation: Purchase and Allocation through Chain Auctions." Journal of Health Politics, Policy and Law 36, no. 4: 717-55.

Rothman, David. 2002. "Ethical and Social Consequences of Selling a Kidney." Journal of the American Medical Association 288, no. 13: 1640-41. 
Rushton, J. Philippe, Roland D. Chrisjohn, and G. Cynthia Fekken. 1981. "The Altruistic Personality and the Self-Report Altruism Scale." Personality and Individual Differences 2, no. 4: 293-302.

Schwindt, Richard, and Aidan Vining. 1998. "Proposal for a Mutual Insurance Pool for Transplant Organs." Journal of Health Politics, Policy and Law 23, no. 5: 725-41.

Spital, Aaron. 2005. "Should People Who Commit Themselves to Organ Donation Be Granted Preferred Status to Receive Organ Transplants?" Clinical Transplantation 19, no. 2: 269-72.

Supphellen, Magne, and Michelle R. Nelson. 2001. "Developing, Exploring, and Validating a Typology of Private Philanthropic Decision Making." Journal of Economic Psychology 22, no. 5: 573-603.

Torjesan, Ingrid. 2018. "Opioid Epidemic Leads to Surge in US Organ Donors, Study Shows.” British Medical Journal 2018, no. 361: k1720.

ULC (Uniform Law Commission). n.d. "Anatomical Gift Act." www.uniformlaws.org /committees/community-home?CommunityKey=015e18ad-4806-4dff-b011-8e1ebc Od1d0f (accessed August 20, 2019).

US Census Bureau. 2017a. "Educational Attainment in the United States: 2017." December 14. www.census.gov/data/tables/2017/demo/education-attainment/cps -detailed-tables.html.

US Census Bureau. 2017b. "The Nation's Median Age Continues to Rise." June 22. www.census.gov/library/visualizations/2017/comm/median-age.html.

US Census Bureau. n.d.-a. "HINC-06. Income Distribution to $\$ 250,000$ or More for Households." www.census.gov/data/tables/time-series/demo/income-poverty/cps -hinc/hinc-06.html (accessed August 20, 2019).

US Census Bureau. n.d.-b. "Current Population Survey (CPS)." www.census.gov /programs-surveys/cps/technical-documentation/complete.html.

US Census Bureau. n.d.-c. "Quick Facts-United States." www.census.gov/quick facts/fact/table/US/PST045218.

Zink, Sheldon, Rachel Zeehandelaar, and Stacey Wertlieb. 2005. "Presumed versus Expressed Consent in the US and Internationally." Virtual Mentor 7, no. 9: 610-14. doi.org/10.1001/virtualmentor.2005.7.9.pfor2-0509.

Zúñiga-Fajuri, Alejandra. 2015. "Increasing Organ Donation by Presumed Consent and Allocation Priority: Chile." Bulletin of the World Health Organization 93, no. 1: 199-202. 
Appendix A Detailed Demographics

\begin{tabular}{|c|c|c|c|c|}
\hline Category & Items & Study 1 & Study 2 & National \\
\hline Sample size & & 201 & 506 & \\
\hline Age, yearsa & Median & 33.00 & 32.00 & 37.90 \\
\hline \multirow[t]{3}{*}{ Gender, \%b } & Male & 47.30 & 55.70 & 49.20 \\
\hline & Female & 52.70 & 43.90 & 50.80 \\
\hline & Other & - & 0.40 & - \\
\hline \multirow[t]{8}{*}{ Political orientation, $\%^{\mathrm{c}}$} & $\begin{array}{l}\text { Far right/extremely } \\
\text { Conservative }\end{array}$ & 5.50 & 1.80 & 3.00 \\
\hline & Right/conservative & 19.40 & 15.80 & 29.00 \\
\hline & Center/moderate & 25.90 & 28.30 & 24.00 \\
\hline & Left/liberal & 29.90 & 33.20 & 23.00 \\
\hline & Far left/extremely liberal & 14.90 & 15.60 & 3.00 \\
\hline & No political view & 4.50 & 4.20 & - \\
\hline & Other political view & - & 1.20 & - \\
\hline & $\begin{array}{l}\text { Unknown/haven't thought } \\
\text { about it }\end{array}$ & - & - & 18.00 \\
\hline \multirow[t]{6}{*}{ Education, $\% \mathrm{~d}$} & Less than high school & - & 0.60 & 11.04 \\
\hline & High school/equivalent & 12.90 & 11.90 & 28.89 \\
\hline & Some college, no degree & 25.90 & 24.90 & 18.86 \\
\hline & Associate's degree & 8.0 & 15.40 & 9.77 \\
\hline & Bachelor's degree & 43.30 & 39.50 & 20.04 \\
\hline & Graduate degree or higher & 10.00 & 7.70 & 11.40 \\
\hline \multirow[t]{5}{*}{ Marital status, $\% \mathrm{e}^{\mathrm{e}}$} & Single, never married & 47.30 & 57.50 & 27.00 \\
\hline & Married & 43.30 & 35.20 & 56.60 \\
\hline & Separated & 1.00 & 1.20 & 2.40 \\
\hline & Widowed & 1.50 & 0.60 & 6.20 \\
\hline & Divorced & 7.00 & 5.50 & 10.40 \\
\hline \multirow[t]{7}{*}{ Household income, $\% \mathrm{f}$} & $<\$ 25 \mathrm{k}$ & 24.40 & 19.80 & 20.23 \\
\hline & $\$ 25 \mathrm{k}-\$ 34,999$ & 11.40 & 16.00 & 9.23 \\
\hline & $\$ 35 \mathrm{k}-\$ 49,999$ & 17.90 & 16.60 & 12.33 \\
\hline & $\$ 50 \mathrm{k}-\$ 74,999$ & 21.40 & 23.50 & 16.45 \\
\hline & $\$ 75 \mathrm{k}-\$ 99,999$ & 12.90 & 14.00 & 12.52 \\
\hline & $\$ 100 k-\$ 149,999$ & 9.50 & 8.10 & 14.49 \\
\hline & $\geq \$ 150 \mathrm{k}$ & 2.50 & 2.00 & 14.76 \\
\hline \multirow[t]{6}{*}{ Ethnicity, \% ${ }^{\mathrm{b}}$} & $\overline{\text { White/Caucasian }}$ & 76.60 & 80.40 & 76.60 \\
\hline & Black/African American & 9.50 & 6.30 & 13.40 \\
\hline & Asian & 5.50 & 7.90 & 5.80 \\
\hline & Hispanic/Latino & 7.00 & 3.80 & 18.10 \\
\hline & Pacific Islander & - & 0.80 & 0.20 \\
\hline & Other & 1.50 & 0.80 & \\
\hline
\end{tabular}

Sources of national data: aUSCB 2017b; bUSCB n.d.-c; cANES n.d.; dUSCB 2017a; eUSCB n.d.-b; fUSCB n.d.-a. 